Research Article

\title{
Experimental Study of the Influence of Excavation Surface Stability and Sand Flowability Caused by Dense Slurry-Earth Pressure Balance Shield Tunneling in Silty Sand Stratum
}

\author{
Yongjin Qian $\mathbb{D}^{\mathbb{D}},{ }^{1,2}$ Fanlu Min $\mathbb{D}^{1,},{ }^{1,2}$ Zhenze Mo $\mathbb{D}^{3},{ }^{3}$ and Xihui Fan $\mathbb{D}^{1,2}$ \\ ${ }^{1}$ College of Civil and Transportation Engineering, Hohai University, Nanjing 210098, China \\ ${ }^{2}$ Key Laboratory of Geomechanics and Embankment Engineering, Ministry of Education, Hohai University, \\ Nanjing 210098, China \\ ${ }^{3}$ Wuxi Metro Group Co., Ltd., Wuxi 214000, China \\ Correspondence should be addressed to Fanlu Min; minfanlu@126.com
}

Received 19 June 2020; Revised 31 July 2020; Accepted 6 August 2020; Published 25 August 2020

Academic Editor: Qiang Tang

Copyright (C) 2020 Yongjin Qian et al. This is an open access article distributed under the Creative Commons Attribution License, which permits unrestricted use, distribution, and reproduction in any medium, provided the original work is properly cited.

\begin{abstract}
Silty sand is highly permeable and has a large internal friction angle. To ensure the stable and efficient construction of the Earth pressure balance (EPB) shield in silt stratum, it is necessary to reduce the disturbance to the stratum during tunneling and reduce the risk of spewing and blocking during soil discharge. Thus, a new type of dense slurry-EPB shield construction technology is proposed. Using a custom-made test device, the consolidation tests were conducted on sand after mixing it with different amounts of slurry to study the change in the pore pressure in the mixed soil and sand stratum and analyze the stress transmission rule. In addition, slump tests were conducted on the mixed soil to study the change in the fluidity. Based on the laboratory test results, a field investigation was carried out to study the effects of the amount of slurry addition on the pore pressure in the stratum, the driving parameters, and the sand's flowability during shield tunneling. The results show that when the amount of slurry reaches a certain value, the filter cake effect occurs. The greater the amount of slurry added during the shield tunneling, the smaller the rate of change of the pore pressure in the stratum. When the amount of BC2 slurry added reached $8 \mathrm{~m}^{3}$ per ring, the rate of change was reduced by $57 \%$, and the slump value improved by $93 \%$. The type of filter cake of the DS-EPB shield was only internal filter cake during tunneling, which reduced the disturbance of the excavation face and improved the flowability of the sand. These results are of great significance to the application and promotion of DS-EPB shields in sandy cobble strata.
\end{abstract}

\section{Introduction}

Earth pressure balance (EPB) shields are widely used in urban rail transit engineering because of their advantages; i.e., they occupy a small land area during construction, they are suitable for tunneling in most strata, and they have simple operation technology in subway and tunnel construction [1-3]. Due to the large change in pressure in the Earth chamber during the excavation of the EPB shield, the excavation surface and stratum are easily disturbed [4-6]. In particular, in the high-permeability sand layer, the stability of the excavation surface during tunneling is difficult to guarantee because of the large permeability, and it is easy for spewing to occur during the soil discharge process [7].
Moreover, because of the large internal friction angle of the sand, the overall flowability of the sand is poor due to the friction between the particles, and the screw conveyor cannot discharge the sand smoothly, causing it to block the soil chamber, which affects the normal excavation of the shield [8-10]. During the construction of Wuxi Metro Line 3 in China, water-rich silt stratum was encountered in many sections [11]. Because there are many high-rise buildings on the upper part, high requirements were required for efficient shield tunneling, stratum disturbance, and surface settlement control.

During the excavation of the EPB shield, the state of discharged soil was improved by adding conditioned materials to the Earth chamber so the soil forms a plastic fluidity 
state, preventing the occurrence of spewing and blocking during the soil discharge process [12]. Vinai et al. [13] and Peila et al. [14] found that the slump of the conditioned soil was linearly increasing with the foam injection when using foam to improve the sandy soil. Guo et al. [15] used a polyacrylamide (PAM) solution to improve the sandy soil and found that PAM could effectively improve the flowability of the sandy soil. Ye [16] found that the fluidity improvement effect of saturated sandy soils after using the slurry mixed with PAM was better than that of using the slurry alone. Jancsecz et al. [17] found that the foam can reduce the cohesion and internal friction angle of the sandy soil. Houlsby and Psomas [18] found that the foam injection can reduce the shear strength of the soil by the direct shear test; $\mathrm{Hu}$ et al. [19] used the bentonite slurry to improve the sand and found that the slurry can reduce the internal friction angle of the sand. Quebaud et al. [12] proposed the permeability coefficients of the sandy soil improved with the foam using a constant head permeability test and found that the foam with a lower foaming rate had a better effect on improving the permeability of sands. Budach and Thewes [20] concluded that the improved permeability coefficient of the sandy soil should be kept below $10^{-3} \mathrm{~cm} / \mathrm{s}$ for at least $1.5 \mathrm{~h}$. Wei [21] analyzed the improvement mechanism of the foam and the bentonite to soils and concluded that the foam occupied the pores in the soil, while the bentonite bounded together with soil particles and formed a low permeable membrane in the pores, both of which could reduce the permeability coefficient of the soil. Qiu et al. [22] used foam, slurry, and polymers to improve sandy soils and found that the foam was less effective in improving the permeability of the soil, while the bentonite and polymers significantly changed the permeability. Huang et al. [23] and Wang et al. [24] investigated the influence of the gradation on the permeability of the foam improved soils and deduced the calculation method of permeability coefficient of the conditioned soil. The above research on the condition of the soil in a sand layer has accumulated a significant amount of practical experience for the discharge of soil in the site, but few studies focus on the effect of the soil condition of the EPB shield on the stability of the excavation surface.

Most studies on the stability control of the excavation surface of a shield tunnel have focused on the slurry shield. Injecting pressurized slurry into the slurry chamber leads to slurry infiltration, and a filter cake will form on the excavation surface to maintain stability $[25,26]$. Watanabe and Yamazaki [27] suggested that as the density of the slurry increased, the filtration loss of the slurry gradually decreased. Fritz [28] found that, adding sands, vermiculites to the slurry can effectively fulfill the requirements of the filter cake formation when conducting an infiltration test on a high permeable sand stratum. Han et al. [29] and Min et al. [30-32] found that the filter cake could be formed rapidly in the highly permeable stratum by using a high-density slurry. Broere [33] and Wei et al. [34] found that the increase of the pore water pressure in the stratum can reduce the effective pressure of the slurry, and the density and particle size of slurry have an important influence on the change of pore water pressure in the stratum. $\mathrm{Xu}$ and Bezuijen [35, 36] studied the influence of the slurry density on the permeability of stratum based on the variation of pore water pressure in the stratum and deduced the formula for calculating the infiltration distance of slurry in the sandy soil. Whether the slurry can be used to maintain the stability of the excavation face of an EPB shield and reduce the disturbance to the stratum requires further study.

In reference to the principle of using slurry to support the excavation face of a slurry shield, a new type of dense slurry shield technology is proposed. High-density slurry and silty sand are mixed in the soil cabin to stabilize the excavation surface so as to reduce the disturbance of the stratum caused by the stress change during the driving of the shield machine. In addition, the slurry can be used to change the flowability and improve the effect of soil discharge. Therefore, after the slurry and sand are mixed, the stress change in the mixed soil layer and the sand stratum must be studied since the change in the fluidity of the mixed soil is still unclear. It is necessary to analyze the effect of the slurry's properties and the amount of slurry added on the changes in the pore pressure and fluidity.

A consolidation test was carried out in the laboratory to analyze the stress change in the sand and the mixed soil after mixing the sand with different amounts of slurry. In addition, soil slump tests were simultaneously conducted to analyze the impact of different slurries on the fluidity of the mixed soil. Then, based on the results of the laboratory test, a field test of the dense slurry-EPB (DS-EPB) shield was carried out in a section of silty sand stratum during the construction of China's Wuxi Metro Line 3. The variation in the tunneling parameters and the pore pressure in the stratum were studied during actual shield tunneling, and the effects of the DS-EPB shield based on the result of the excavation surface stability control and the soil conditions were determined.

\section{Laboratory Test}

2.1. Materials and Methods. The main materials used to prepare the slurries used in the experiment were Ca-bentonite, clay, sodium carboxymethyl cellulose (CMC), sodium carbonate, and distilled water. The slurry's density and bleeding rate were controlled during the preparation process. The density was measured using a 1002 type slurry specific gravity scale, the viscosity was measured using a Markov funnel viscometer, and the $24 \mathrm{~h}$ bleeding rate was determined using a $1000 \mathrm{ml}$ measuring cylinder. The proportions and properties of the test slurries are presented in Table 1. A small amount of a $2 \%$ aqueous solution of CMC and sodium carbonate powder was added to adjust the viscosity of the slurry [37]. The grain-size distribution curves of the slurries were measured using the laser particle sizer [38], shown in Figure 1. The clay contents $(<0.005 \mathrm{~mm})$ of the slurries were about $30 \%$, and the silt particle contents $(<0.075 \mathrm{~mm})$ were greater than $97 \%$.

The soil sample used as the tested silt was excavated onsite, washed, dried, and passed through a geosieve. The sample's grain-size distribution is shown in Figure 1. The $>0.075 \mathrm{~mm}$ particles in the soil accounted for $61 \%$, and the 
TABle 1: Proportions and physical parameters of the testing slurry.

\begin{tabular}{lccccc}
\hline Name & Bentonite $(\%)$ & Clay $(\%)$ & Density $\left(\mathrm{g} / \mathrm{cm}^{3}\right)$ & Funnel viscosity $(\mathrm{s})$ & $24 \mathrm{~h}$ bleeding rate $(\%)$ \\
\hline BC1 & 15.38 & 7.69 & 1.16 & 38 & 0 \\
BC2 & 14.18 & 14.89 & 1.20 & 45 & 0 \\
BC3 & 12.82 & 23.08 & 1.25 & 53 & 0 \\
\hline
\end{tabular}

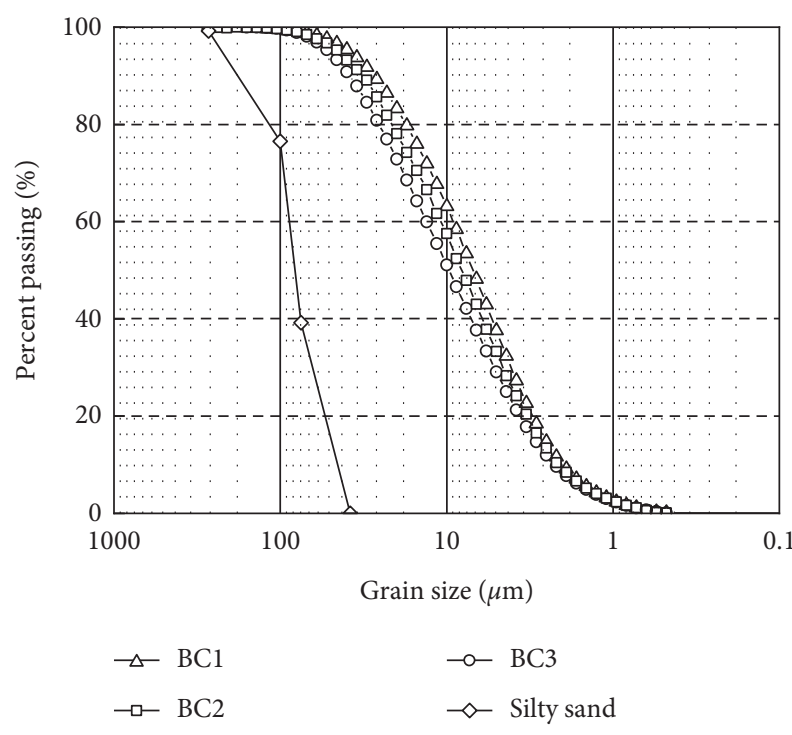

FIGURE 1: Grain-size distribution curve of slurries and silty sand.

physical and mechanical properties of silty sand are shown in Table 2.

A conventional one-dimensional test soil column was used. A gasbag with a diameter of $9 \mathrm{~cm}$ made of rubber membrane was added, and the air pressure acted uniformly on the surface of the mixed soil through the airbag. The conditions of a stratum near the excavation face during shield tunneling were simulated. The device consisted of a plexiglass column, pressurization equipment, and a datacollection system. The side wall contained three measuring holes, which were connected to the pore pressure transducers (L1, L2, and L3). Transducers L1 and L2 were used to record the change in the pore pressure in the sand layer, and L2 was closer to the interface between the sand layer and the mixed soil layer. Transducer L3 was used to record the change in the pore pressure in the mixed soil layer. The position of the measuring holes is shown in Figure 2.

Before the test began, the bottom of the test column was filled with coarse sand with a particle size of $2-5 \mathrm{~mm}$ and a height of $5 \mathrm{~cm}$, which was used as a filter layer to prevent clogging of the drainage hole. Then, silty sand was added to the column above the filter layer three times to reach a height of $30 \mathrm{~cm}$. The dry density of the stratum was controlled by layer compaction, and fresh water was injected slowly from the drain at the bottom of the column to saturate the formation. After mixing the prepared slurry according to $10 \%$, $15 \%, 20 \%, 23 \%$, and $25 \%$ of the quantity of the silt, $20 \mathrm{~cm}$ of highly mixed soil was evenly loaded into the column. A customized rubber membrane was installed and fixed onto the flange plate with a sealing ring, the flange cover was
Table 2: Physical and mechanical parameters of silty sand.

\begin{tabular}{lccccc}
\hline Soil & $\rho\left(\mathrm{g} / \mathrm{cm}^{3}\right)$ & $c(\mathrm{kPa})$ & $\varphi\left({ }^{\circ}\right)$ & $k(\mathrm{~cm} / \mathrm{s})$ & $\omega(\%)$ \\
\hline Silty sand & 1.92 & 3 & 32.4 & $3.5 \times 10^{-3}$ & 29 \\
\hline
\end{tabular}

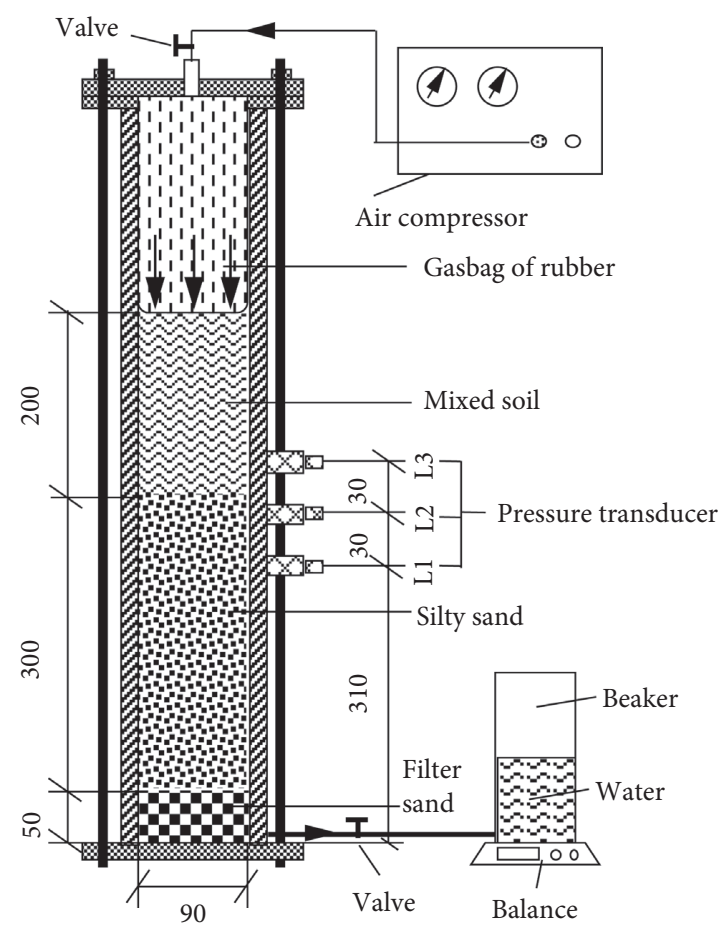

FIgURE 2: Schematic of the modified infiltration test apparatus (units: $\mathrm{mm}$ ).

installed, $5 \mathrm{kPa}$ of air pressure was applied in advance, the air between the rubber membrane and the side wall of the column was discharged, the flange was sealed, the column was pressurized to the set pressure, the bottom drain hole was opened, and the changes in the pore pressure in the sand layer and in the mixed soil layer were measured. The test applied three levels of pressure in sequence, i.e., 50, 100, and $200 \mathrm{kPa}$. The variation in the pore pressure in the Earth chamber and the sand stratum under the effect of different Earth pressures on the stratum was simulated.

Simultaneously with the consolidation test conducted on the slurry mixed soil, the prepared mixed soil was subjected to a slump test. The slump test was performed three times for each group of additions, and the average value was recorded.

2.2. Results and Analysis. After the silt was mixed with slurry of different qualities, the pore water pressure in the mixed soil layer and silt layer under pressure exhibited a large 
difference with the change of the slurry mixing amount. This difference is found in all three kinds of slurries. Taking BC2 slurry as an example, the variation of pore water pressure of the mixed soil layer was analyzed. Figure 3 shows the variation of pore water pressure at the L3 mixed soil layer. It can be found that as the proportion of slurry increases, the dissipation rate of pore water pressure in the mixed soil layer gradually decreases. When the amount of mixed slurry is $10 \%$ of the mass of silt, the excess water pore pressure dissipates quickly under the action of additional stress, and, according to the principle of effective stress, the total stress applied to the mixed soil layer at this time is almost supported by the effective stress. When the amount of slurry added gradually increases, under the impact of various pressures, the excess pore water pressure in the mixed soil layer has not completely dissipated, and the dissipation amount gradually decreases. The total stress applied in the mixed soil layer is jointly supported by pore water pressure and effective stress. When the slurry mixing amount is $25 \%$ of the mass of the silt, under the pressure of all levels, the excess pore water pressure dissipates very little and the additional stress is almost borne by the pore water pressure. The above two phenomena can also be found in the tests of the other two kinds of slurries, indicating that the change of the mixing amount plays an important role in the stress transmission in the mixed soil layer.

The pore water pressure in the silt layer also exhibited a certain difference with the change in the amount of slurry in the mixture. The change in the pore water pressure in the silt layer is shown in Figure 4. Pressure is exerted on the surface layer under the effect of $50 \mathrm{kPa}$ of stress at L2, i.e., $1 \mathrm{~cm}$ below the surface. As the amount of slurry added to the mixture increases, the dissipation rate of the pore pressure at L2 gradually decreases. At $10 \%$ slurry, the pore pressure dissipation rate is the fastest. When $25 \%$ slurry is used, the pore pressure dissipation rate is the slowest, but the final dissipation amount is almost the same. This phenomenon occurs for different types of slurries and in other stress tests.

Due to its large permeability coefficient, silty sand can quickly dissipate once excess pore pressure is generated in the formation. As the amount of slurry in the mixed soil layer increased, the slurry infiltrated into the silt layer under stress. During the infiltration process, the fine particles continued to block part of the pores in the silt layer, and thus, the permeability coefficient of the slurry infiltrated zone gradually decreased, as did the dissipation rate of excess pore pressure. As the amount of slurry added gradually increased, the fine particle content blocking the pores increased, and the permeability of the original layer decreased, forming a new low-permeability zone, similar to the law of pore pressure dissipation when the slurry infiltrated into the soil [30].

The slurries with different properties had a certain effect on the dissipation of the pore pressure. Three kinds of slurries were mixed with the silt at $20 \%$ and $23 \%$ by mass to analyze the change in the pore pressure in the mixed soil layer under $50 \mathrm{kPa}$ of stress, as shown in Figures 5(a) and 5(b). The pore pressure in the mixed soil layer dissipated the fastest for the BC1 slurry, and the slowest for the BC3. For

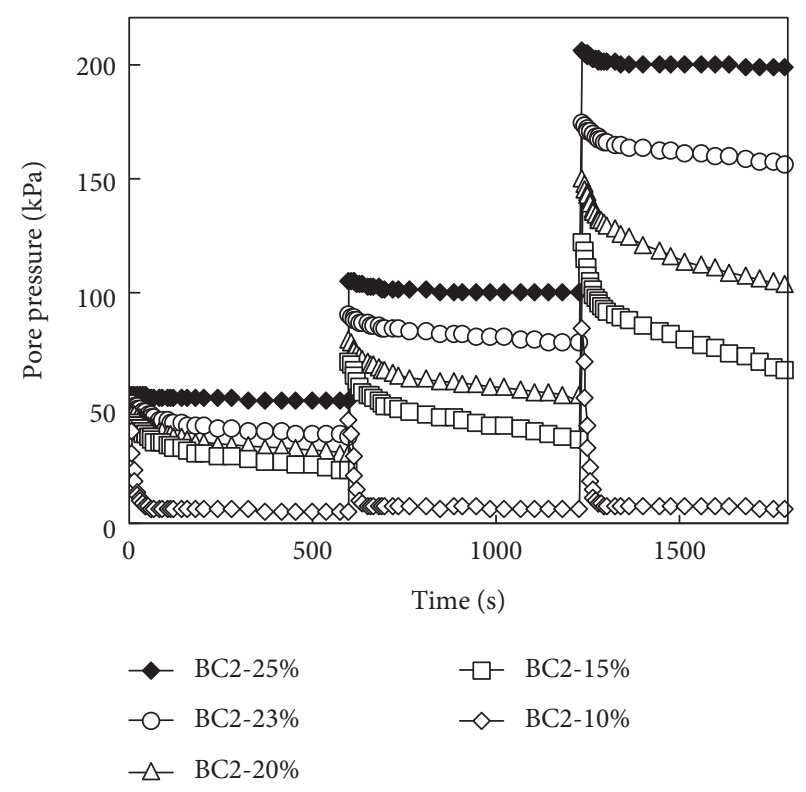

FIGURE 3: Dissipation of the pore water pressure in mixed soil layer with different slurry mixed.

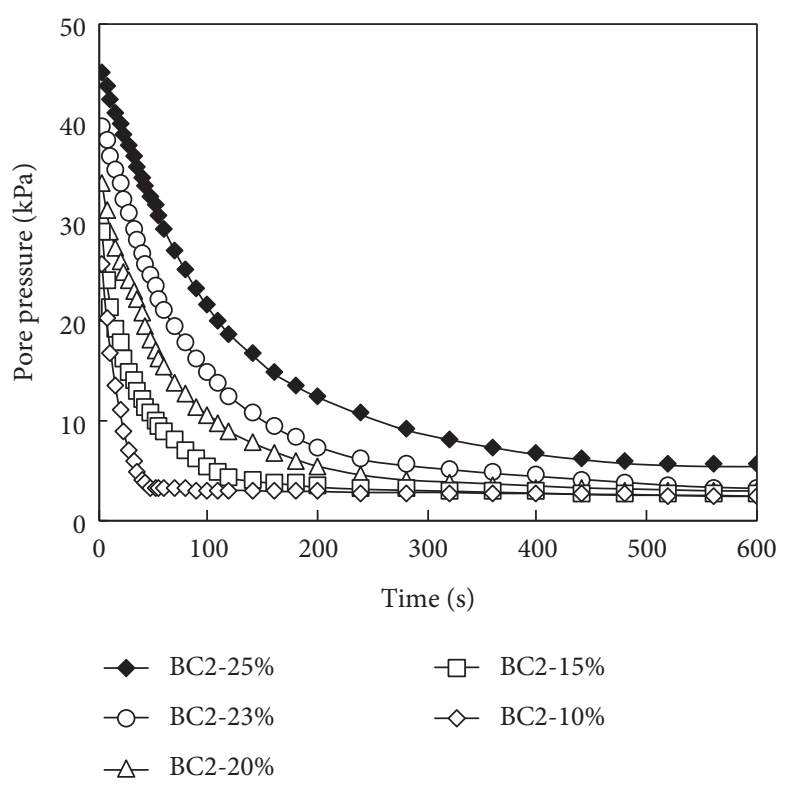

FIGURE 4: Dissipation of pore water pressure in the silt layer for different slurry mixtures.

the $20 \%$ incorporation of the three kinds of slurries (Figure 5(a)), the final pore pressure dissipation in the mixed soil layer was quite different, and the dissipation rate of the BC1 slurry exceeded $80 \%$. For $23 \%$ incorporation (Figure 5(b)), the pore pressure dissipated in the mixed soil layer of the $\mathrm{BC} 2$ and $\mathrm{BC} 3$ slurries relatively slowly, and the dissipation rate was less than $25 \%$. The dissipation of the BC3 mixed soil still exceeded 50\%. As the density and viscosity of the slurry increased, the permeability coefficient of the mixed soil layer gradually decreased, and the pore pressure dissipation rate gradually decreased. 

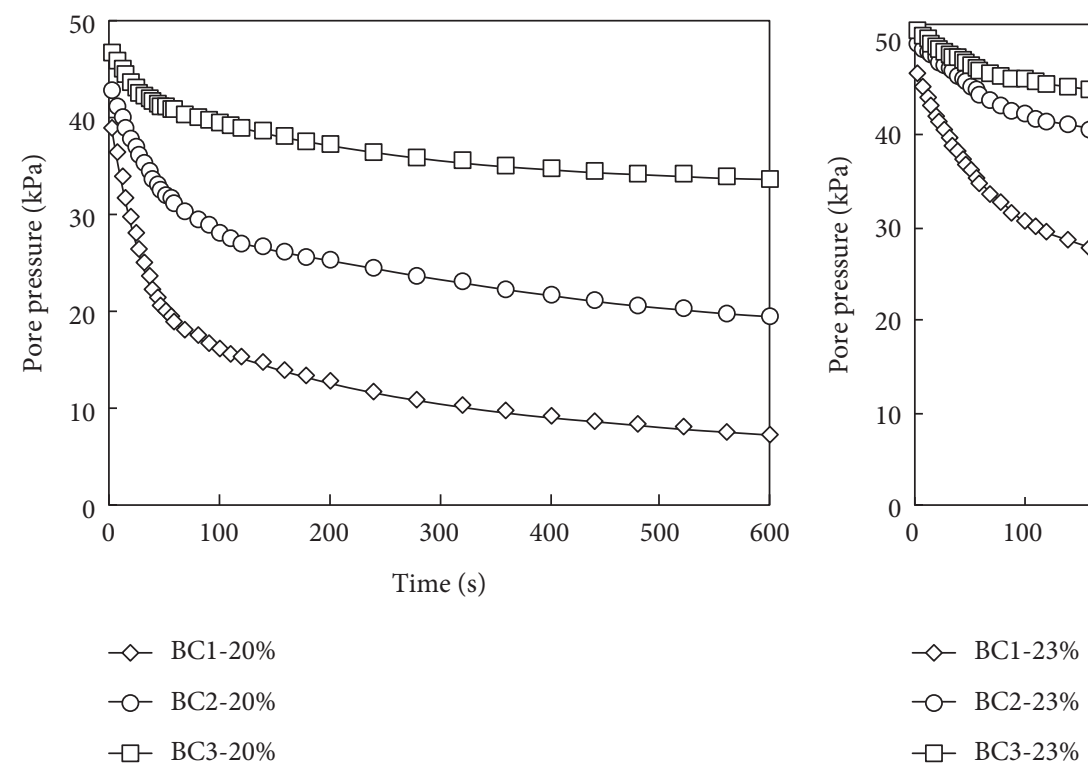

(a)

(b)

Figure 5: Dissipation of pore water pressure in the mixed soil layer for the different types of slurries.

Further analysis of the variation in the pore pressure at L2 in the mixed soil layer with the $23 \%$ incorporation of the three slurries (Figure 6) revealed that the pore pressure in the surface layer quickly dissipated after the $\mathrm{BC} 1$ slurry was incorporated and that the $\mathrm{BC} 1$ slurry had a small effect on the permeability of the silt layer. The pore pressure dissipation rates of the surface layer exhibited a clear difference for the $\mathrm{BC} 2$ and $\mathrm{BC} 3$ slurries. The $\mathrm{BC} 3$ slurry dissipated the slowest, and the $\mathrm{BC} 2$ and $\mathrm{BC} 3$ slurries had a certain effect on the permeability of the stratum. This phenomenon occurred under other stresses and additions because as the density and viscosity increased, the influence of the mixed soil layer infiltration on the surface layer increased.

The slump test results of the mixed soil for different slurry blending amounts were analyzed (Figure 7). As can be seen, as the amount of slurry added increased, the slump and the fluidity of the mixed soil gradually increased. Furthermore, for the same slurry mixing amount, when the soil was mixed with different types of slurry, the slump of the soil exhibited large differences. The slump for the $\mathrm{BC} 1$ slurry mixture was greater than that for the BC3 slurry mixture. Several scholars have shown that when the slump of sand is $150-200 \mathrm{~mm}$, its flowability meets the discharge requirements of the screw conveyor [14, 39]. As can be seen from the laboratory test results, the $\mathrm{BC} 1$ slurry mixture content range that meets the discharge requirements is $10 \%-20 \%$, that of the $\mathrm{BC} 2$ slurry is $12 \%-23 \%$, and that of the $\mathrm{BC} 3$ slurry is $15 \%-24 \%$.

\section{Field Test Experiment}

3.1. Project Overview. The length of the shield section between Yongle East Road (YLD) Station and Jinhaili (JHL) Station on Wuxi Metro Line 3 is about $852.76 \mathrm{~m}$, and it mainly passes through a water-rich silty sand layer,

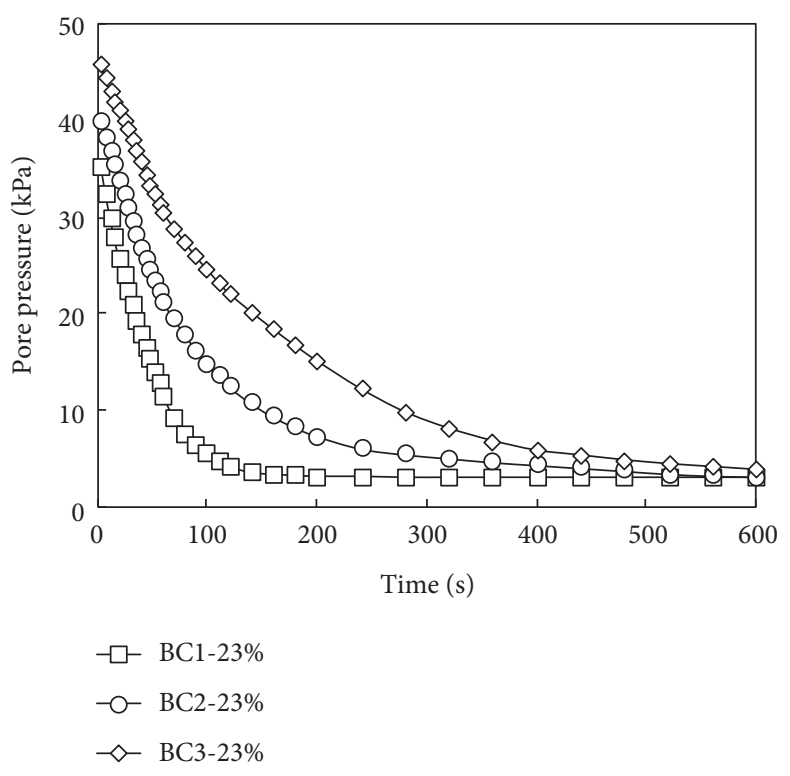

FIGURE 6: Dissipation of pore water pressure in the silt layer for the different types of slurries.

accounting for more than $50 \%$ of the total shield section length. The maximum soil cover depth is $15.1 \mathrm{~m}$, and the minimum soil cover depth is $9.5 \mathrm{~m}$. The strata in the tunnel crossing area are mainly (4) 1 clayey silt, (4) 2 silty sand, (5) silty clay, and (6) 1 clay (Figure 8). The overall geological section of the tunnel is shown in Figure 7. The groundwater is abundant at the site, and the stable diving water level is $0.78-1.50 \mathrm{~m}$ below the ground. The groundwater is mainly replenished by atmospheric precipitation, and surface water and tap water are also added along the line. The groundwater runoff conditions are good, and the permeability of the silty sand layer is about $3.5 \times 10^{-3} \mathrm{~cm} / \mathrm{s}$. The crossing section 


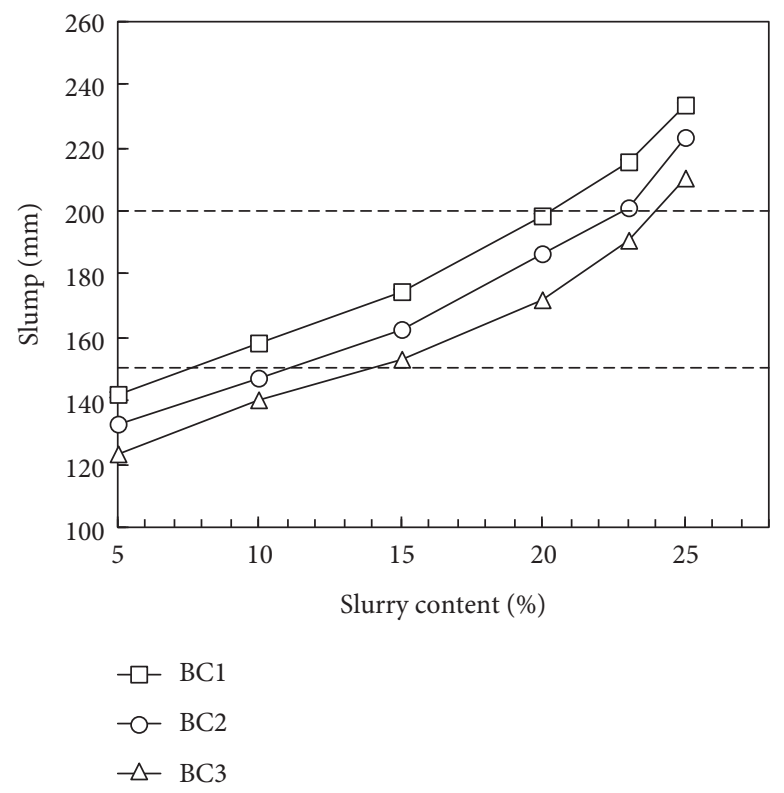

Figure 7: Slump changes for different amounts of slurry.

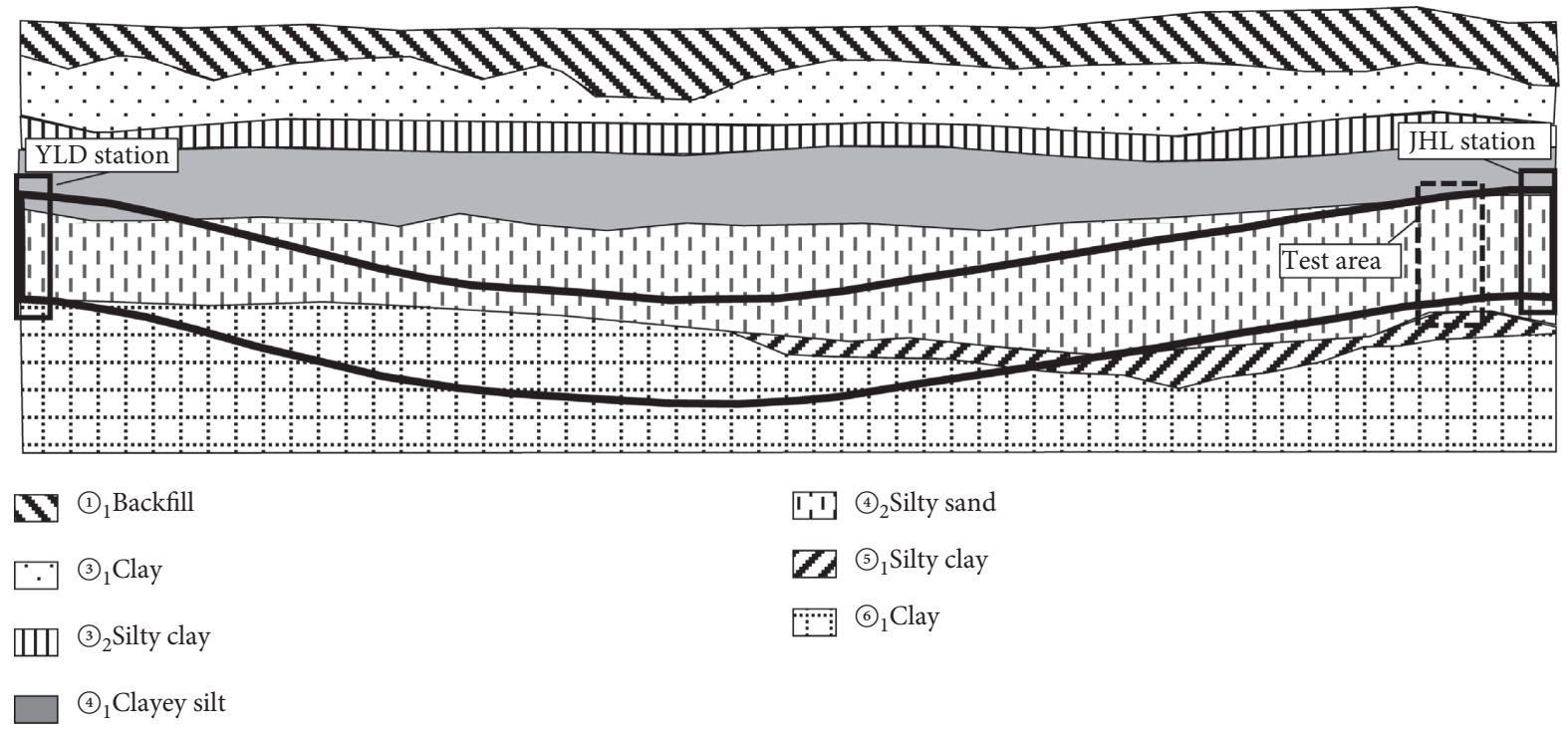

Figure 8: Geological section map.

contains a microconfined aquifer in the (4) 1 clayey silt layer and (4) 2 the silty sand layer. The basic geotechnical parameters of the soils are presented in Table 3 . The tunnel was constructed with an EPB shield with a diameter of $6.44 \mathrm{~m}$, the maximum power of the cutter head was $630 \mathrm{~kW}$, the maximum thrust of the cutter head was $42,000 \mathrm{kN}$, and the maximum torque was $6200 \mathrm{kNm}$. The cutter head opening rate was 35\%, and the designed maximum driving speed was $80 \mathrm{~mm} / \mathrm{min}$.

3.2. Test Program. Based on the results of the laboratory tests, the full section silty sand layer in ring nos. 673-679 in front of the receiving well of Jinhaili Station was used as the field test area. Because there is no pore pressure monitoring device in the Earth chamber of the shield machine, it is difficult to measure the variation in the pore pressure. Therefore, the change in the pore water pressure in the stratum in front of the shield excavation face was taken as the site research object. During the test, the pore pressure data were obtained using a preburied pore pressure transducer. The transducer used in this study was a vibrating wire sensor with a range of $0-200 \mathrm{kPa}$ that can accurately measure the pore pressure in the stratum in real time (Figure 9). The depth of the buried hole was $11-12 \mathrm{~m}$ below the surface, which is within the longitudinal excavation range of the cutter head of the shield (Figure 10). After the transducer was buried, the borehole was back-filled with coarse sand and sealed with grout. The on-site pore pressure data were divided into two sections. The data 
TABLE 3: Geotechnical parameters of the in situ soil.

\begin{tabular}{|c|c|c|c|c|c|}
\hline Soil layer name & $\gamma_{\text {sat }}\left(\mathrm{kN} / \mathrm{m}^{3}\right)$ & $e$ & $c(\mathrm{kPa})$ & $\varphi\left({ }^{\circ}\right)$ & $k(\mathrm{~cm} / \mathrm{s})$ \\
\hline (1) ${ }_{1}$ Backfill & 19.1 & 0.810 & 13.2 & 15.6 & N/A \\
\hline (3) ${ }_{1}$ Clay & 20.0 & 0.720 & 58.6 & 17.4 & $2.90 \times 10^{-7}$ \\
\hline (3) ${ }_{2}$ Silty clay & 19.3 & 0.824 & 29.6 & 17.8 & $1.40 \times 10^{-5}$ \\
\hline (4) ${ }_{1}$ Clayey silt & 19.2 & 0.808 & 10.5 & 30.8 & $3.20 \times 10^{-4}$ \\
\hline (4) ${ }_{2}$ Silty sand & 19.2 & 0.802 & 5.7 & 32.4 & $3.52 \times 10^{-3}$ \\
\hline (5) ${ }_{1}$ Silty clay & 19.3 & 0.833 & 25.1 & 16.1 & $4.60 \times 10^{-6}$ \\
\hline (6) ${ }_{1}$ Clay & 20.3 & 0.670 & 60.1 & 17.8 & $6.30 \times 10^{-7}$ \\
\hline
\end{tabular}

Note: N/A = not available, $\gamma_{\text {sat }}$ is the saturated unit weight; $e$ is the void ratio; $c$ and $\varphi$ are the effective cohesion force and the friction angle type, respectively; and $k$ is the permeability.

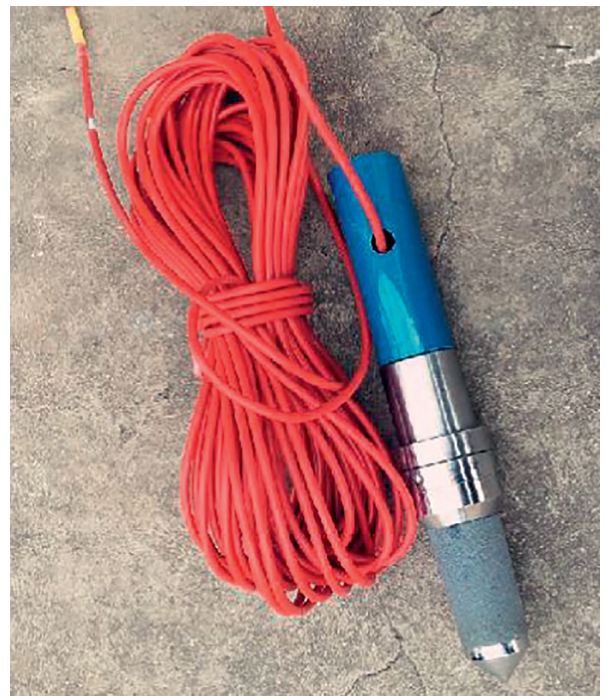

(a)

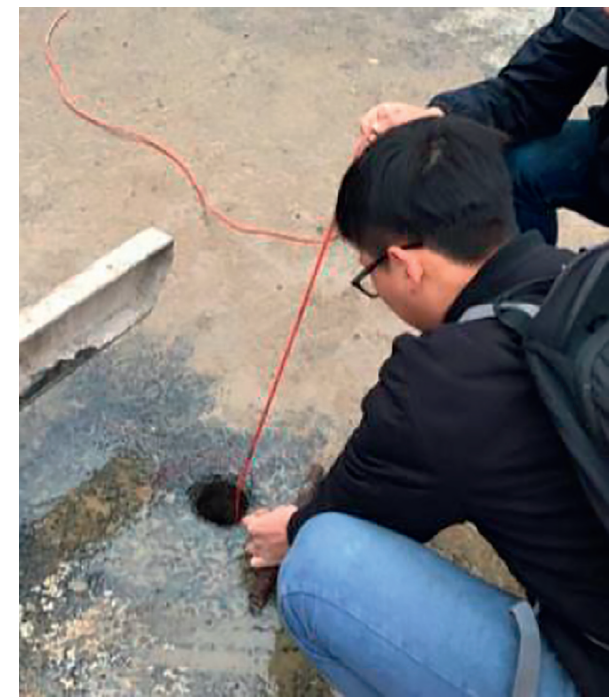

(b)

Figure 9: Setting of pore pressure transducer.

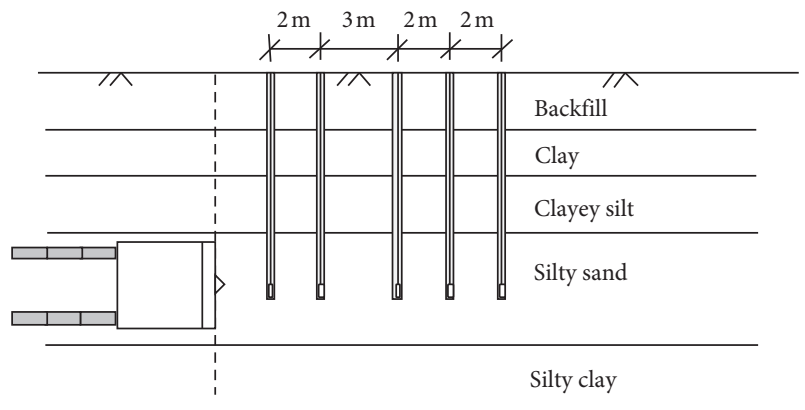

FIGURE 10: Geological section sketch map of test area.

were read and recorded every 2 min during the shield tunneling and every $10 \mathrm{~min}$ after the shield stopped driving. The test section was continuously monitored, and the variation in the pore pressure of the silty layer in front of the excavation surface was recorded during the shield tunneling in the test area (ring nos. 673-679).

To study the influence of the slurry addition on the tunneling parameters during tunnel construction, the torque, thrust, and speed of the cutter head were recorded during the shield tunneling in the test area, soil was collected for a slump test during the sand discharge, and the flowability was recorded. In addition, observation points were set up at the surface tunnel axis of ring nos. 668 and 678 to monitor the settlement during the shield tunneling.

The test area was mainly divided into two sections, of which ring nos. 673-675 comprised the normal tunneling area, and ring nos. 676-679 comprised the slurry-added test area. According to the pumping capacity of the shield machine and the results of the laboratory test, the test slurryaddition scheme was designed to tunnel two rings (ring nos. 676 and 677), and $4 \mathrm{~m}^{3}$ (approximately $6.5 \%$ of the slurry content) per ring and then $8 \mathrm{~m}^{3}$ (approximately 13\% of the slurry content) of slurry in ring nos. 678 and 679 were injected (Figure 11). Due to the rudimentary of the on-site slurry mixing equipment, after mixing with the BC3 slurry, a considerable amount of clay lumps was still found, while the number of lumps was very small and avoidable when the BC2 slurry was made, so the BC2 slurry was selected for the experiment. The slurry density was $1.2 \mathrm{~g} / \mathrm{cm}^{3}$, and the viscosity was $45 \mathrm{~s}$ (Figure 12).

\subsection{Measurement Results and Analysis}

3.3.1. Pore Pressure in Stratum. During the shield tunneling in the silty sand, the pore water pressure of the stratum 


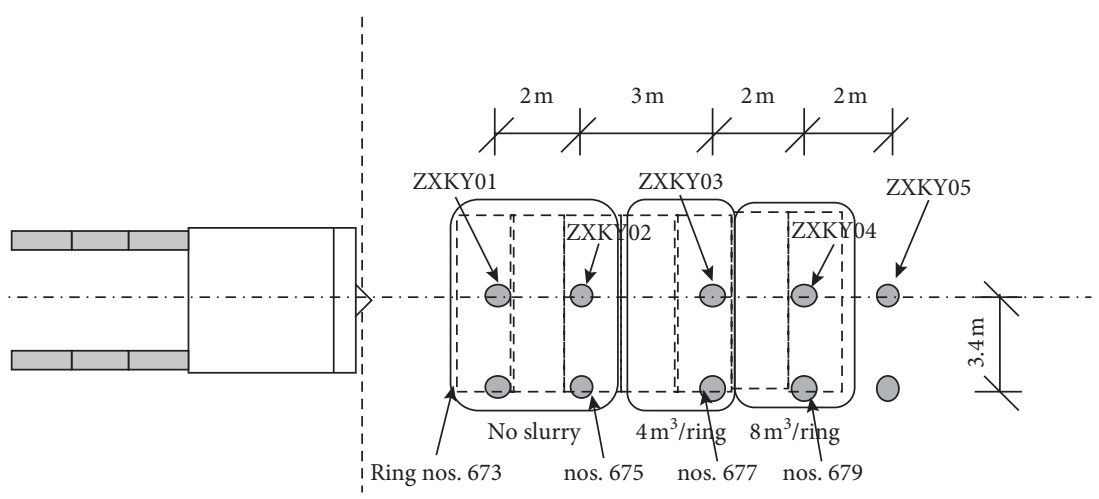

FIGURE 11: Schematic of the sensors and slurry addition.

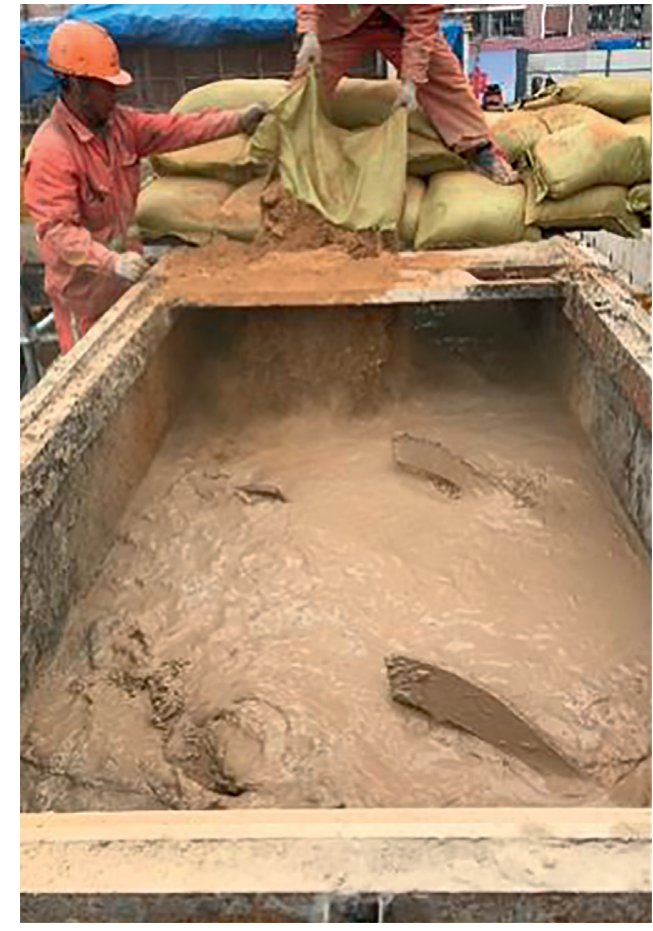

(a)

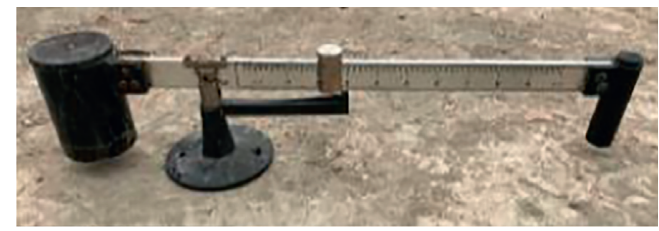

(b)

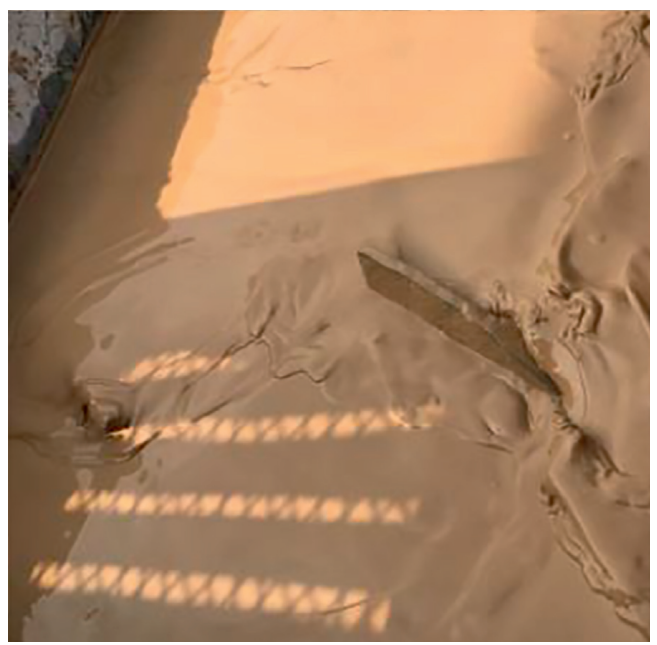

(c)

FiguRe 12: In situ slurry preparation. 
initially increased and then decreased as the shield advanced, and then, it stopped (Figure 13). In particular, when the shield was driving, due to the continuous action of the cutter head and jacks, a large amount of pore water pressure was generated in the formation. Because the upper and lower parts of the silty layer in the test area are clay layers, during the normal excavation process, the pore pressure generated in the silt layer did not quickly dissipate. Due to the different distances between the transducer and the cutter head of the shield, the pore pressure generated at every transducer during the tunneling process was different. The maximum pore pressure was $180 \mathrm{kPa}$, measured by ZXKY01 (transducer-01, pore water pressure of the tunnel axis). After the shield stopped driving, all the pore pressure transducers gradually decreased to the initial value (about $83 \mathrm{kPa}$ ). When $4 \mathrm{~m}^{3}$ of slurry per ring was added for tunneling (ring nos. 676 and 677), the maximum pore pressure was $147 \mathrm{kPa}$. The maximum pore pressure was $131 \mathrm{kPa}$ when $8 \mathrm{~m}^{3}$ of slurry per ring was added. After the addition of the slurry, the change in the pore pressure in the silt layer during shield tunneling gradually decreased, and the addition of the slurry decreased the pore pressure in the Earth chamber, causing it to dissipate into the silt layer. This is consistent with the change in the pore pressure in the stratum when the slurry was added in the laboratory test.

During the shield tunneling, the distance between the cutter head and the sensors constantly changed; the pore pressures at the five sensors during the tunneling and the distance between the cutter head and sensors were sorted out as shown in Figure 14. As can be seen from the figure, as the distance decreased, the pore pressure continued to increase. The changes in the pore pressure in the area without slurry were measured by ZXKY01. When the sensor was close to the cutter head, the maximum value was $180 \mathrm{kPa}$, which is $116 \%$ larger than the initial value of the layer. The pore pressure variation recorded by ZXKY03 can be divided into two parts. The first is approximately $2000-5500 \mathrm{~mm}$ (without slurry added). As the distance decreased, the pore pressure increased from 102 to $140 \mathrm{kPa}$. The second part is $0-2000 \mathrm{~mm}$ (with $4 \mathrm{~m}^{3}$ of slurry added per ring). As the distance decreased, the pore pressure increased from 108 to $149 \mathrm{kPa}$, and the maximum value was $80 \%$ larger than the initial value. The change curves of the pore pressures measured by ZXKY04 and ZXKY05 can be divided into three parts. Taking ZXKY04 as an example, the first part was larger than $4000 \mathrm{~mm}$ (without slurry), the second was

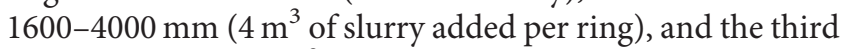
was $0-1600 \mathrm{~mm}\left(8 \mathrm{~m}^{3}\right.$ of slurry added per ring). The pore pressure of the third part changed from 110 to $132 \mathrm{kPa}$. The maximum pore pressure value was $59 \%$ greater than the initial value, which was $57 \%$ less than that without the addition of slurry $(180 \mathrm{kPa})$.

The addition of slurry induced obvious changes in the pore pressure at the same distance. The data from the three sensors (ZXKY02, ZXKY04, and ZXKY05) in the range of $1600-3500 \mathrm{~mm}$ were selected for investigation. When the shield was driving in this range, ZXKY02 corresponded to no slurry added, ZXKY04 corresponded to excavation with $4 \mathrm{~m}^{3}$ of slurry added per ring, and ZXKY05 corresponded to

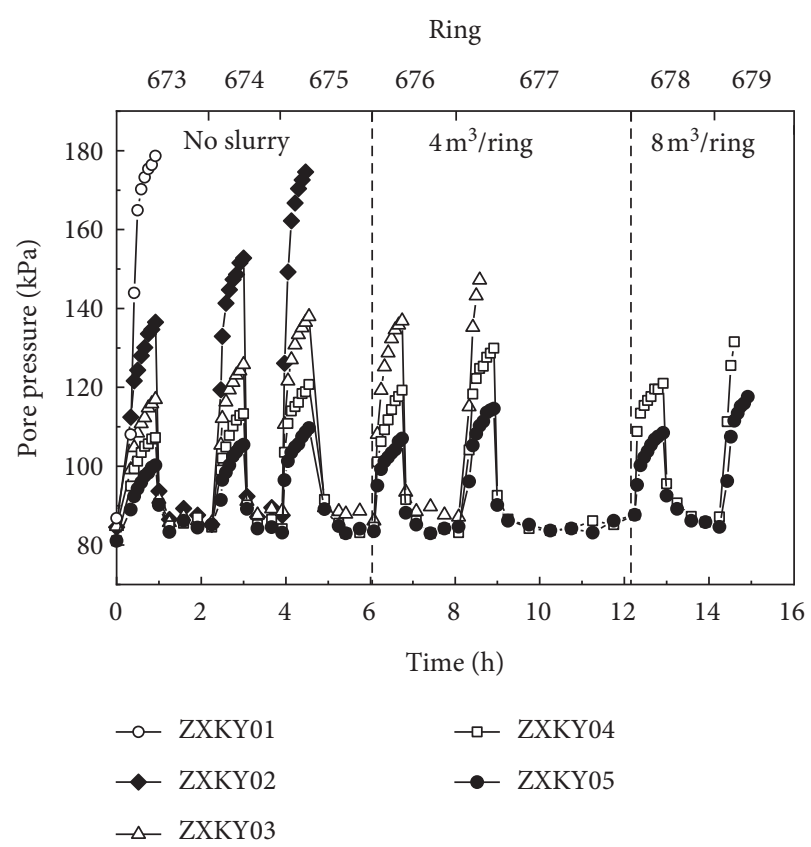

FIGURE 13: Pore pressure change with time during shield tunneling.

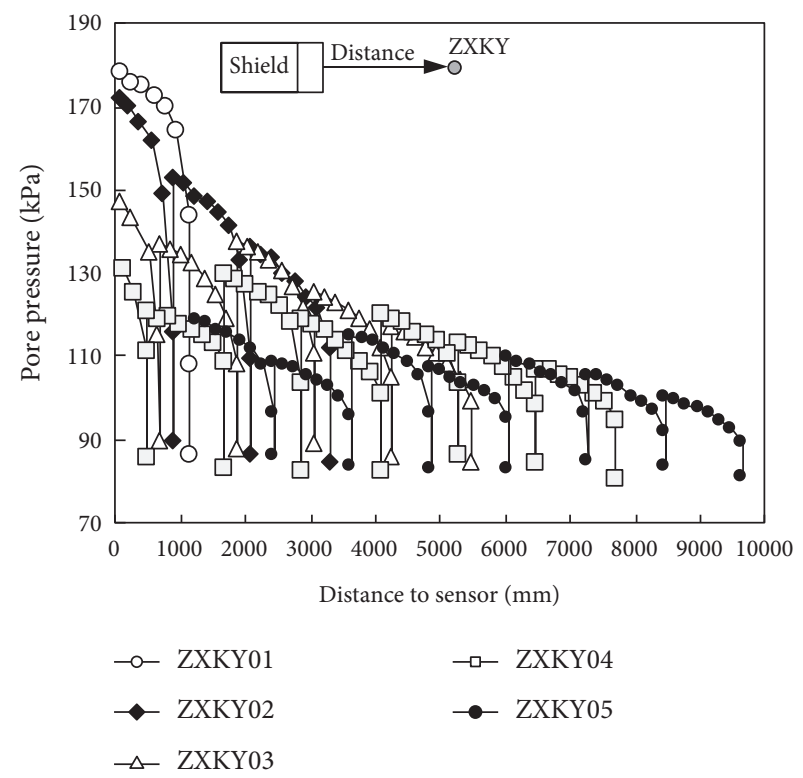

FIgUre 14: Pore pressure change with distance during shield tunneling.

$8 \mathrm{~m}^{3}$ of slurry added per ring (Figure 15). As can be seen from the figure, the change at ZXKY02 $(123-145 \mathrm{kPa})$ was the largest at the same distance; and the change at ZXKY05 $(102-118 \mathrm{kPa})$ was the smallest.

The ratio of the pore pressure during tunneling to the initial pore pressure is defined as the rate of change of the pore pressure. Within the range of $1600-3500 \mathrm{~mm}$, as the distance decreased, the rate of change of the pore pressure gradually increased. When slurry was not added, the rate of change of the pore pressure was approximately $48-80 \%$. When $4 \mathrm{~m}^{3}$ of slurry was added per ring, the rate of change of 


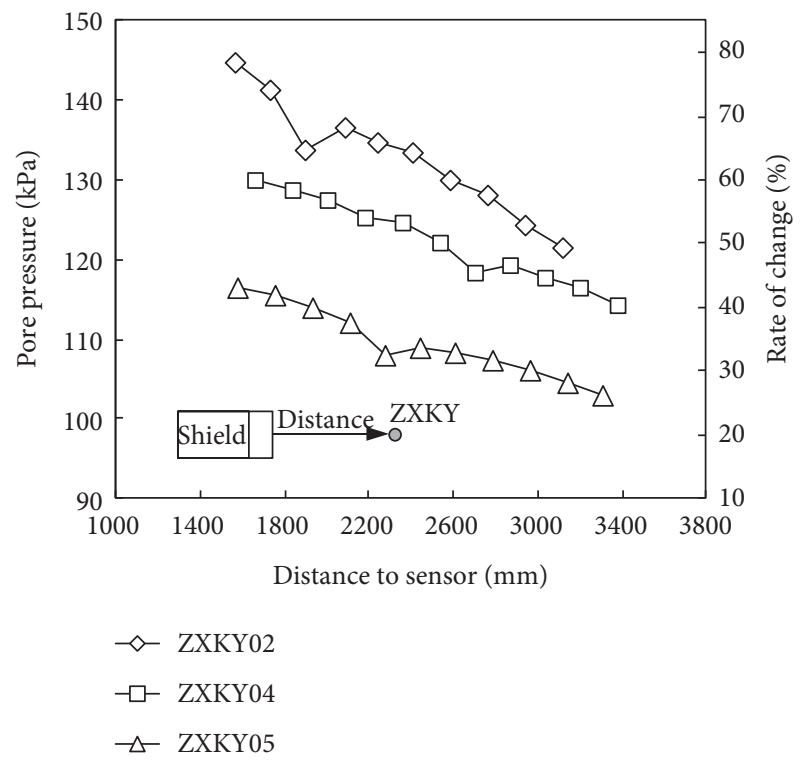

FIGURE 15: Influence of the slurry volume on the pore pressure.

the pore pressure was approximately $40-60 \%$, and the rate of change of the pore pressure gradually decreased.

3.3.2. Tunneling Parameters. The main tunneling parameters of a shield are torque, thrust, tunneling speed, and Earth pressure. Figure 16 shows the relationship between the thrust and torque of the shield for different amounts of slurry. As can be seen from the figure, there is a good correlation between torque and thrust. As the thrust increased, the torque of the cutter head gradually increased. Within the same thrust range, the torque of the cutter head was maintained at $3200-4500 \mathrm{kNm}$ when driving without the addition of slurry. When slurry was added, the torque was significantly reduced. The cutter-head torque was maintained at $2600-4000 \mathrm{kNm}$ when tunneling with $4 \mathrm{~m}^{3}$ of slurry added per ring. When $8 \mathrm{~m}^{3}$ of slurry per ring was added, the torque was maintained at $2000-3200 \mathrm{kNm}$. Therefore, it is considered that after, mixing the slurry into the Earth chamber, the slurry has a lubricating effect on the excavation surface. Under the same thrust, the torque during shield tunneling was greatly reduced.

Figure 17 shows the relationship between the tunneling speed and torque. During normal tunneling, the torque and tunneling speed were also positively correlated. The torque without slurry was maintained at $3200-4500 \mathrm{kNm}$; when tunneling with $4 \mathrm{~m}^{3}$ of slurry added per ring, the torque was maintained at $2400-4000 \mathrm{kNm}$. For $8 \mathrm{~m}^{3}$ of slurry added per ring, the torque was maintained at $2000-3600 \mathrm{kNm}$. After the addition of slurry, the changes in the tunneling parameters, such as the torque and the tunneling speed of the shield, were beneficial to shield tunneling.

3.3.3. Flowability of the Discharged Sand. During the field test, the discharged sand was sampled, and slump tests were conducted. The status of discharged sand in the Earth chamber was observed with time. Figure 18(a) shows the

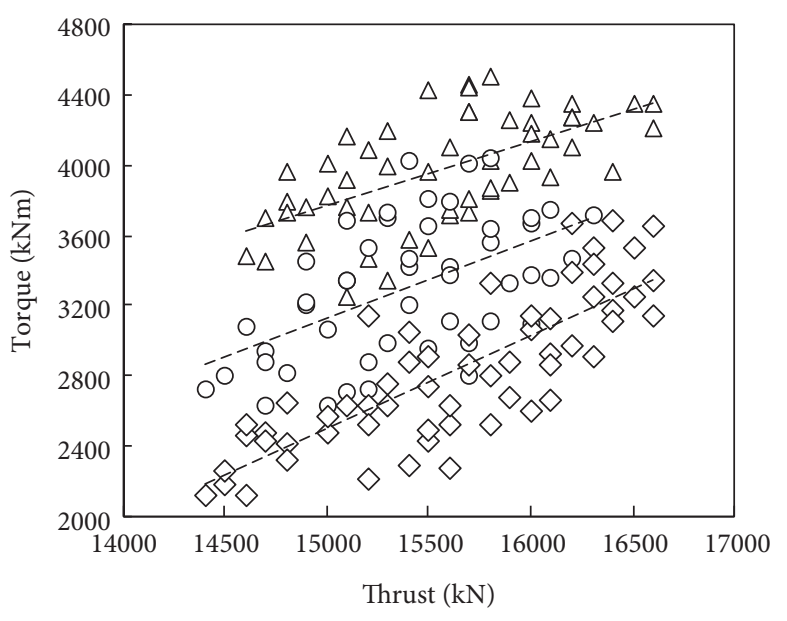

$$
\begin{aligned}
& \Delta \text { No slurry } \\
& \bigcirc 4 \mathrm{~m}^{3} / \text { ring } \\
& \diamond 8 \mathrm{~m}^{3} / \text { ring }
\end{aligned}
$$

FIGURE 16: Correlation between thrust and torque.

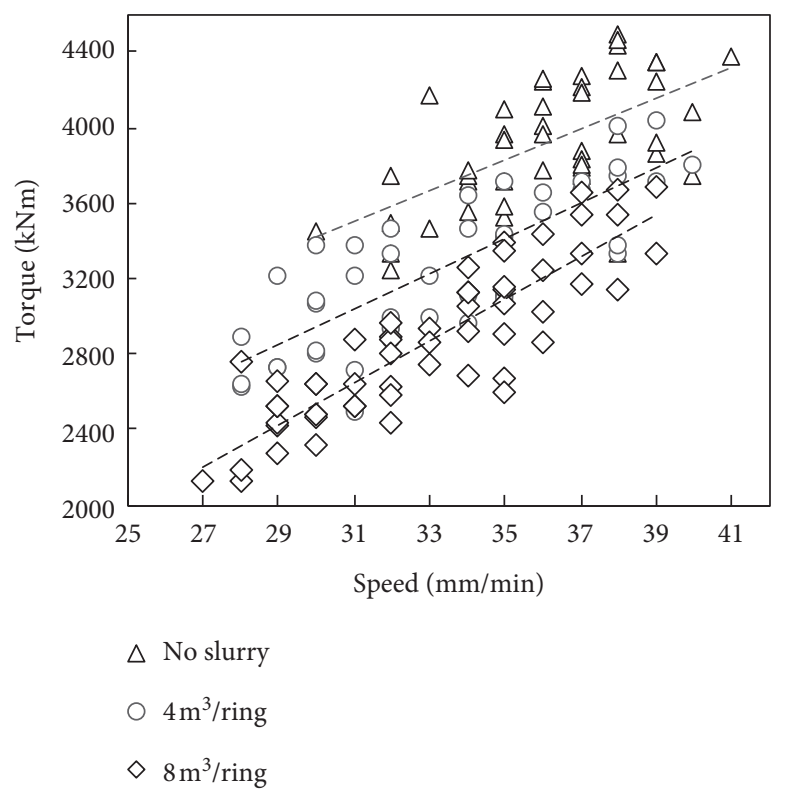

Figure 17: Correlation between speed and torque.

results for the sand discharged from the Earth chamber without mixing slurry, and it can be seen that the flowability of the soil is poor. The slump test was carried out after the sampling (Figure 18(b)). It was found that when tunneling without mixing slurry, the average slump value of the soil was $85 \mathrm{~mm}$, which does not reach the appropriate state of discharge (Figure 7). After $8 \mathrm{~m}^{3}$ of slurry per ring was added (about 13\% of the slurry content), the silty sand had good fluidity (Figure 18(c)), and another slump test was performed (Figure 18(d)). The average slump value of the soil was $164 \mathrm{~mm}$, i.e., $93 \%$ greater than the soil without slurry, which is a significant improvement over the flowability without slurry. The slump value for the same slurry content 


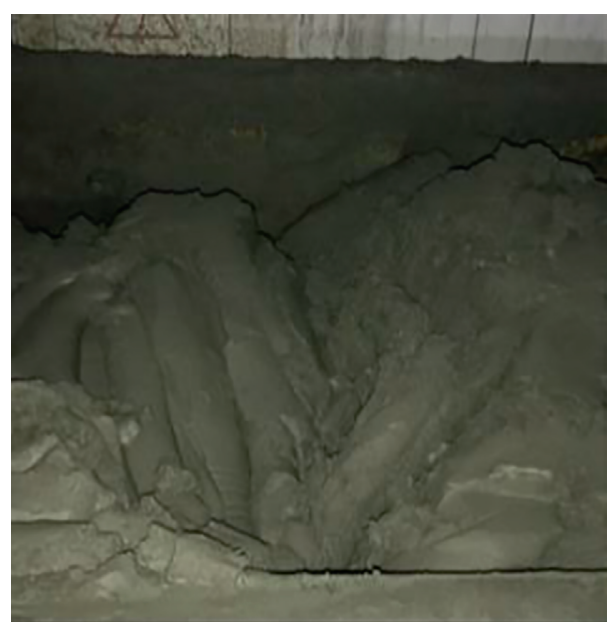

(a)

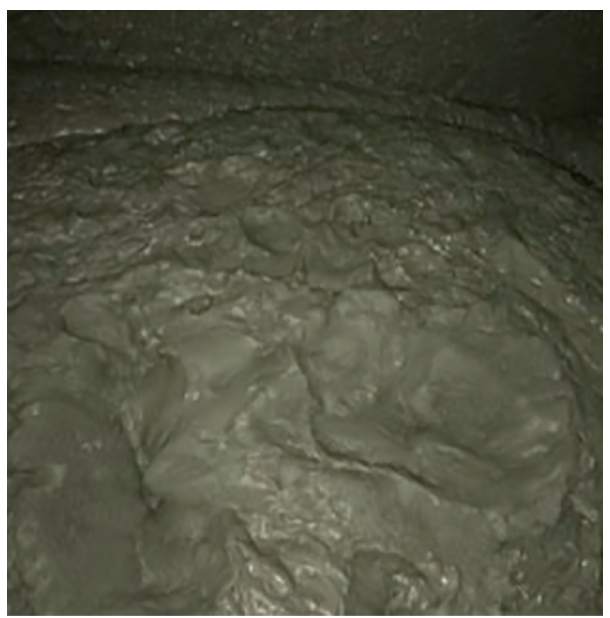

(c)

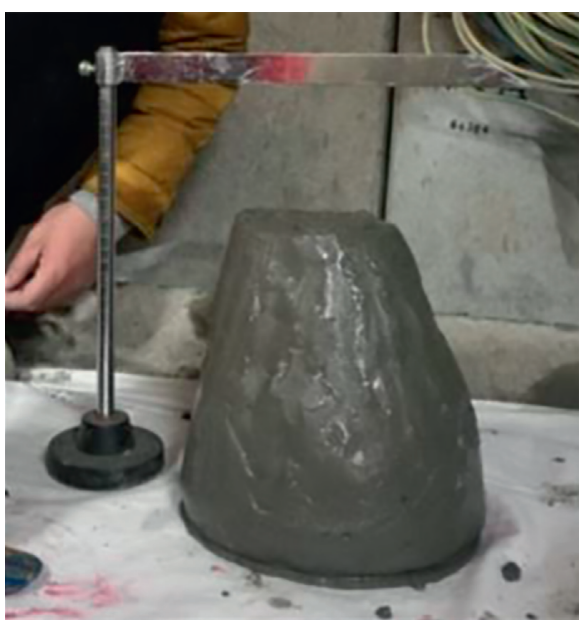

(b)

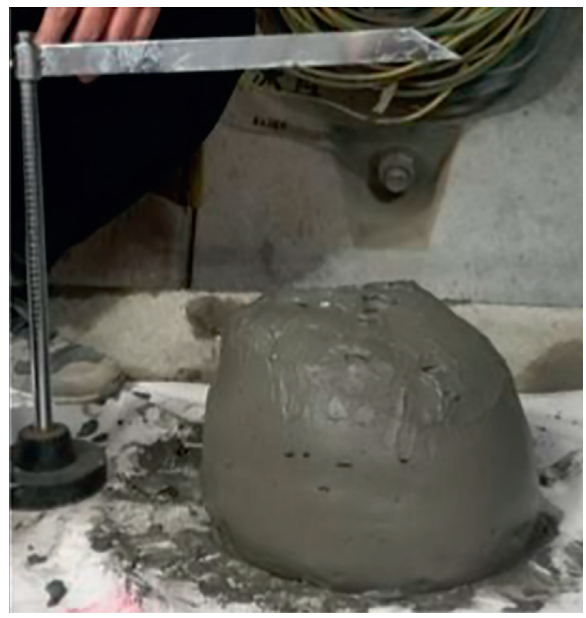

(d)

FIGURE 18: Slump test of the discharged sand.

in the laboratory test $(157 \mathrm{~mm})$ is almost the same as that of the field test (Figure 7).

\section{Discussion}

As can be seen from the laboratory test results, the mixed soil layer was consolidated under the application of additional stress, and when the amount of slurry in the mixed soil layer reached a certain ratio, the excess pore pressure partially converted into effective stress, and together with the remaining excess pore pressure it supported the additional stress. During the consolidation process, part of the slurry particles infiltrated into the layer along with the interstitial water, blocking the pores of the surface part of the sand stratum, which reduced the permeability of this part of the layer. As the amount of slurry in the mixed soil layer increased, the slurry particles aggregated to the bottom of the mixed soil layer, blocking the pores in the bottom of the layer and further slowing the dissipation of the pore pressure in the other parts of the mixed soil. The pore pressure generated in the other parts of the sand layer dissipated quickly. This situation is similar to the slurry infiltration in the sand layer, which produced a low-permeability filter cake. The pore pressure slowly dissipates above the filter cake, but no obvious external filter cake could be observed in the mixed soil layer and silt layer because of the consolidation. This phenomenon was called the filter cake effect. The generation of this effect is similar to the mechanism of slurry infiltration and filter cake formation in a slurry shield, but the slurry particles' infiltration and the formation of the filter cake are different from those for slurries infiltrating sand. Min et al. [30] investigated slurry infiltration and filter formation, and they determined that, in addition to the pore size of the stratum, filter cake formation also has important relationships with the density, viscosity, and particle gradation of the slurry. The most important factor is the blocking effect of slurry particles on the stratum pores. Therefore, both the filter cake of the slurry shield and the filter cake effect of the DS-EPB shield are due to the slurry particles blocking the stratum pores, which changes the permeability of the layer. The difference in the filter cake effect is that some of the slurry particles in the mixed soil layer infiltrate into the sand layer under the stress, and the infiltration process is accompanied by the consolidation of the mixed soil layer. 
During the consolidation, the slurry infiltrated zone (internal filter cake) in the silt layer could be vaguely observed. The filter cake formation of the slurry shield involves the infiltration of a large amount of slurry fluid into the sand layer. During the infiltration process, the accumulation of slurry particles in the surface layer and the formation of a filter cake can be observed [36].

The results of the field test and the pore pressure records indicate that the rate of change of the pore pressure in the stratum caused by normal tunneling without slurry was as high as $116 \%$. When using DS-EPB shield tunneling, the rate of change of the pore pressure in the formation was significantly reduced. As the slurry mixing amount increased, the maximum rate of change decreased to $59 \%$, which is $57 \%$ less than that of conventional tunneling. The generated filter cake effect is an important reason for the decrease in the rate of change. The field slump test showed that the addition of slurry improves the flowability of silty sand. Combined with the laboratory test results, the slump test results of the samples collected during the field experiments were $7 \mathrm{~mm}$ larger than those in the laboratory for the same slurry type and addition amount. Because the groundwater around the shield shell and the cutter head easily penetrates into the soil chamber during the shield tunneling in the sand layer, the water content of the discharged sand is higher than that of the actual sand stratum. Therefore, the slump test results of the sand collected on-site were larger than those of the laboratory tests. However, the laboratory slump test can still predict the field sand's flowability, but the test results are conservative.

Due to the limitation of the pumping capacity of the EPB shield, the use of the BC3 slurry has the risk of pipe blockage. In addition, when the amount of BC2 slurry injected reached $8 \mathrm{~m}^{3}$, the maximum pumping capacity of the shield was reached, so it is impossible to conduct field tests for a larger amount of slurry. During the shield tunneling, a certain amount of pore pressure change still occurred in the layer behind the excavation face. The pumping capacity will be improved in the future, and the amount of slurry added during the field tests will continue to increase. Because the particles in the stratum are relatively uniform and small when tunneling in the silty layer, the filter cake effect on the improvement of the stratum is not significant. When the shield is excavated in the sandy cobble stratum, due to the poor self-stability, the slurry added to the Earth chamber effectively blocks the pores of the stratum and produces a more significant filter cake effect, which maintains the stability of the excavation surface better. Further research will be conducted on sandy cobble stratum.

\section{Conclusions}

(1) After silty sand is mixed with a certain proportion of slurry, under the application of additional stress, the mixed soil layer is consolidated, and the slurry in the mixed soil layer infiltrates into the sand stratum along with the interstitial water, resulting in the filter cake effect. The excess pore pressure of the mixed soil layer passes through the filter cake and slowly dissipates into the sand layer. The filter cake effect produced in the DS-EPB shield is similar to that in the slurry shield, but the filter cake could hardly be observed because of the consolidation.

(2) The greater the amount of slurry added, the more obvious the filter cake effect, and the smaller the rate of change of the pore pressure in the sand stratum, the greater the flowability of the discharged sand. Excessive fluidity is not conducive to discharging soil, so it is necessary to optimize the amount of slurry added to the mixture. When using BC2 slurry driving with $8 \mathrm{~m}^{3}$ of slurry added per ring, the maximum rate of change of the pore pressure was $59 \%$, which is $57 \%$ less than that in conventional tunneling.

(3) DS-EPB shield tunneling reduces the disturbance of the stratum caused by the pore pressure generated during normal excavation. The testing of DS-EPB shield tunneling in silty sand stratum indicates that a certain amount of slurry can not only improve the stability of the excavation surface and reduce the disturbance of the silt stratum but also improve the flowability of the sand and ensure that it can be discharged better. This finding is of great significance to the application and promotion of DS-EPB shields in sandy cobble stratum.

\section{Data Availability}

The data used to support the findings of this study are available from the corresponding author upon request.

\section{Conflicts of Interest}

The authors declare that they have no conflicts of interest regarding the publication of this paper.

\section{Acknowledgments}

This study was supported by the National Natural Science Foundation of China (51778213) and the Fundamental Research Funds for the Central Universities of China (B200202073).

\section{References}

[1] G. Anagnostou and K. Kovári, "Face stability conditions with earth-pressure-balanced shields," Tunnelling and Underground Space Technology, vol. 11, no. 2, pp. 165-173, 1996.

[2] X. Li, S. Zhou, and H. Di, "Observed ground pressure acting on the lining of a large-diameter shield tunnel in sandy stratum under high water pressure," Advances in Civil Engineering, vol. 2020, Article ID 3091528, 12 pages, 2020.

[3] L. Li, S. Sun, J. Wang, S. Song, Z. Fang, and M. Zhang, "Development of compound EPB shield model test system for studying the water inrushes in karst regions," Tunnelling and Underground Space Technology, vol. 101, 2020.

[4] D. Zhang, Q. Li, Q. Fang, and L. Chen, "Deformation mechanism and prediction method for tunneling in complex 
urban ground conditions," Chinese Journal of Rock Mechanics and Engineering, vol. 33, no. 12, pp. 2504-2516, 2014.

[5] Q. Xu, H. Zhu, W. Ding, and X. Ge, "Laboratory model tests and field investigations of EPB shield machine tunnelling in soft ground in Shanghai," Tunnelling and Underground Space Technology, vol. 26, no. 1, pp. 1-14, 2011.

[6] L. Li, S. Sun, J. Wang, W. Yang, S. Song, and Z. Fang, "Experimental study of the precursor information of the water inrush in shield tunnels due to the proximity of a water-filled cave," International Journal of Rock Mechanics and Mining Sciences, vol. 130, 2020.

[7] G. Zheng, X. Dai, and Y. Diao, "Parameter analysis of water flow during EPBS tunnelling and an evaluation method of spewing failure based on a simplified model," Engineering Failure Analysis, vol. 58, no. 1, pp. 96-112, 2015.

[8] K. Feng, C. He, Y. Qiu et al., "Full-scale tests on bending behavior of segmental joints for large underwater shield tunnels," Tunnelling and Underground Space Technology, vol. 75, pp. 100-116, 2018.

[9] Y. Tang, Y. Song, N. Zhou, Y. Huang, W. Ye, and Q. Zhang, "Experimental research on troubles of EPB shield construction in sandy soil," Chinese Journal of Rock Mechanics and Engineering, vol. 24, no. 1, pp. 52-56, 2005.

[10] Y. Qian, W. Zhu, F. Min, R. Du, and C. Wang, "Test of construction method of EPB shield with filter membrane supporting in sand and cobble stratum," China Journal of Highway and Transport, vol. 30, no. 8, pp. 210-215, 2017.

[11] Z. Mo, M. Wang, H. Li, Y. Qian, G. Luo, and H. Wang, "Laboratory investigation on pore water pressure variation caused by filter cake effect during slurry-EPB shield tunneling in silty sand layer," Rock and Soil Mechanics, vol. 40, no. 6, pp. 2257-2263, 2019.

[12] S. Quebaud, M. Sibai, and J.-P. Henry, "Use of chemical foam for improvements in drilling by earth-pressure balanced shields in granular soils," Tunnelling and Underground Space Technology, vol. 13, no. 2, pp. 173-180, 1998.

[13] R. Vinai, C. Oggeri, and D. Peila, "Soil conditioning of sand for EPB applications: a laboratory research," Tunnelling and Underground Space Technology, vol. 23, no. 3, pp. 308-317, 2008.

[14] D. Peila, C. Oggeri, and L. Borio, "Using the slump test to assess the behavior of conditioned soil for EPB tunneling," Environmental and Engineering Geoscience, vol. 15, no. 3, pp. 167-174, 2009.

[15] F. Guo, Z. Zhao, J. Zhang, X. Yang, and X. Yuan, "Experimental study of ground conditioning of pure sand stratum by using polymer," Tunnel Construction, vol. 37, no. S1, pp. 53-58, 2017.

[16] C. Ye, "Study of ground conditioning technology for earth pressure balance (EPB) shield used in high water pressure and high permeability sandy stratum," Tunnel Construction, vol. 38, no. 2, pp. 300-307, 2018.

[17] S. Jancsecz, R. Krause, and L. Langmaack, "Advantages of soil conditioning in shield tunneling: experiences of LRTS Izmir," in Proceedings of the International Congress on Challenges for the 21st Century, Balkema, Oslo, Norway, pp. 865-875, June 1999.

[18] G. Houlsby and S. Psomas, G. Houlsby and S. Psomas, "Soil conditioning for pipejackingand tunnelling: properties of sand/foam mixtures," in Proceedings of Underground Construction, Taylor \& Francis, pp. 128-138, 2001.

[19] C. Hu, Y. Cui, X. Wang, S. Gong, and W. Zhang, "Soil improvement for earth pressure balance shields construction in full section sand layer," Xi'an University of Architecture and
Technology: Natural Science Edition, vol. 45, no. 6, pp. 761766, 2013.

[20] C. Budach and M. Thewes, "Application ranges of EPB shields in coarse ground based on laboratory research," Tunnelling and Underground Space Technology, vol. 50, pp. 296-304, 2015.

[21] K. WEI, "Micro-mechanism analysis for the soil improvement by foam and bentonite in EPB shield tunneling," Modern Tunnelling Technology, vol. 44, no. 1, pp. 73-77, 2007.

[22] Y. Qiu, X. Yang, Z. Tang, and Y. Li, "Soil improvement for earth pressure balance shields construction in watered sandy stratum," Journal of Tongji University: Natural Science, vol. 43, no. 11, pp. 1703-1708, 2015.

[23] S. Huang, S. Wang, C. Xu, Y. Shi, and F. Ye, "Effect of grain gradation on the permeability characteristics of coarsegrained soil conditioned with foam for EPB shield tunneling," Ksce Journal of Civil Engineering, vol. 23, no. 11, pp. 46624674, 2019.

[24] S. Wang, S. Huang, T. Qiu, J. Yang, J. Zhong, and Q. Hu, "Analytical study of the permeability of a foam-conditioned soil," International Journal of Geomechanics, vol. 20, no. 8, 2020.

[25] X. Li and D. Yuan, "Creating a working space for modifying and maintaining the cutterhead of a large-diameter slurry shield: a case study of Beijing railway tunnel construction," Tunnelling and Underground Space Technology, vol. 72, pp. 73-83, 2018.

[26] F. Min, H. Song, and N. Zhang, "Experimental study on fluid properties of slurry and its influence on slurry infiltration in sand stratum," Applied Clay Science, vol. 161, pp. 64-69, 2018.

[27] T. Watanabe and H. Yamazaki, "Giant size slurry shield is a success in Tokyo," Tunnels Tunnelling International, vol. 13, no. 1 , pp. 13-17, 1981.

[28] P. Fritz, "Additives for slurry shields in highly permeable ground," Rock Mechanics and Rock Engineering, vol. 40, no. 1, pp. 81-95, 2007.

[29] X. R. Han, W. Zhu, and Q. W. Liu, "Influence of slurry property on filter cake quality on working face of slurry shield," Rock and Soil Mechanics, vol. 29, pp. 288-292, 2008.

[30] F. Min, W. Zhu, and X. Han, "Filter cake formation for slurry shield tunneling in highly permeable sand," Tunnelling and Underground Space Technology, vol. 38, pp. 423-430, 2013.

[31] F. Min, W. Zhu, C. Lin, and X. Guo, "Opening the excavation chamber of the large-diameter size slurry shield: a case study in Nanjing Yangtze River Tunnel in China," Tunnelling and Underground Space Technology, vol. 46, pp. 18-27, 2015.

[32] F. Min, J. Du, N. Zhang et al., "Experimental study on property change of slurry and filter cake of slurry shield under seawater intrusion," Tunnelling and Underground Space Technology, vol. 88, pp. 290-299, 2019.

[33] W. Broere, "Influence of excess pore pressures on the stability of the tunnel face," in Proceedings of Geotechnical Aspects of Underground Construction in Soft Ground, pp. 179-184, Toulouse, France, October 2002.

[34] D. Wei, W. Zhu, and F. Min, "Experimental study of forming time of filter cake and conversion rate of slurry pressure in slurry shield in sand stratum," Rock and Soil Mechanics, vol. 35, no. 2, pp. 423-428, 2014.

[35] T. Xu and A. Bezuijen, "Analytical methods in predicting excess pore water pressure in front of slurry shield in saturated sandy ground," Tunnelling and Underground Space Technology, vol. 73, pp. 203-211, 2018.

[36] T. Xu and A. Bezuijen, "Experimental study on the mechanisms of bentonite slurry penetration in front of a slurry 
TBM," Tunnelling and Underground Space Technology, vol. 93, Article ID 103052, 2019.

[37] F. Min, X. Wang, M. Li, Y. Ni, E. Al-qadhi, and J. Zhang, "Preparation of high porosity and high strength ceramisites from municipal sludge using starch and $\mathrm{CaCO} 3$ as a combined poreorming agent," Journal of Materials in Civil Engineering, 2020, In Press.

[38] Z. Zhao, M. Benzerzour, N.-E. Abriak, D. Damidot, L. Courard, and D. Wang, "Use of uncontaminated marine sediments in mortar and concrete by partial substitution of cement," Cement and Concrete Composites, vol. 93, pp. 155-162, 2018.

[39] D. Martinelli, D. Peila, and E. Campa, "Feasibility study of tar sands conditioning for earth pressure balance tunnelling," Journal of Rock Mechanics and Geotechnical Engineering, vol. 7, no. 6, pp. 684-690, 2015. 